\title{
Design and Implementation of User-specific Information Service Applying Beacon and Internet of Things Technologies at Education Sites
}

\author{
Hyun Joo Kim ${ }^{1}$ and Min Sun Kim${ }^{2}$ \\ ${ }^{1}$ Dept. of Electronics \& Electrical Engineering Dan-kook University, Korea, \\ ${ }^{2}$ School of Tourism and Distribution Management, Hyupsung University, Korea \\ ${ }^{1}$ chopinkhj@gmail.com, ${ }^{2}$ sunnyminkim@hanmail.net
}

\begin{abstract}
Beacons can provide various application services such as context awareness related to objects, content push, indoor location technology, and auto check in, and thus, it is emerging as a core technology that supports the amalgamation of online and off-line services. Moreover, a demand for Internet of Things (IoT) services is constantly increasing. Among Internet of Things (IoT) technologies, beacon service technology is receiving particular attention because it can generate new, diverse services for customers. Above all, beacon service serves as both a reference point that provides location-related information and a milestone for supporting beacon location technology. Furthermore, as beacons can be effectively used as an information enhancement service and indoor location technology, they are expected to be useful for business marketing. In this study, an education information service for use in universities was designed and implemented with a focus on the location technology offered by beacon and Internet of Things (IoT) technologies. Indeed, educational sites intend to provide various information services to the consumers they support with education. It is anticipated that beacon and Internet of Things (IoT) technologies can be used to facilitate the configuration of an application service that assists the supply of information services.
\end{abstract}

Keywords: Internet of Things, IoT, Beacon, Education Sites IoT Technologies

\section{Introduction}

With the advent of Internet of Things (IoT) technology, the demand for services that automate information services through communication between objects is constantly increasing. We can say that the era of IoT has arrived. Accordingly, IoT technology has been a major issue in industries for a long time. IoT facilitates realtime data exchange through the installation of sensors on an object, and this technology connected to physical objects such as electronic circuits, software, cars, and buildings can easily be found near us [1-2]. Beacons are one such technology; they are used for various application services such as context awareness related to objects, content push, indoor location technology, and auto check in, and they are thus emerging as a core technology that supports the amalgamation of online and off-line services. Among Internet of Things (IoT) technologies, beacon service technology is receiving particular attention because it can generate new, diverse services for customers. Above all, beacon service serves as both a reference point that provides location-related information and a milestone for supporting beacon location technology. Furthermore, as beacons can be effectively used as an information enhancement service and indoor location technology, they are expected to be useful for business marketing. Universities that provide a variety of education

Received (June 15, 2017), Review Result (August 11, 2017), Accepted (September 29, 2017) 
information services are also showing interest in IoT information services. They are also trying to hold a dominant position in terms of the University Informatization plan by using these services and supply customized information services that provide university members with desired information in the right place at the right time. When information is transferred unilaterally regardless of the purpose for its use, users tend to regard it as spam. For this reason, universities are focusing on developing services that provide users with desired information at the desired time.

This study concentrates on the location technology included in the beacon and IoT technologies and applies it to education information services. Moreover, it implemented an education information service by utilizing specific beacon-related technologies such as context awareness, content push, indoor location technology, and auto check in. In addition, it designed and implemented an education information service that facilitates the utilization of IoT-based beacon information services at education sites. To provide an implementation example, this study designed and implemented a smart education information system that receives information such as classroom information, classroom location, class time, automatic attendance, notices at university, scholarship guidance, library information, academic calendar, building information, and mobile payment in smart devices possessed by university members and provides them with desired information.

\section{Research}

Beacon service is a communication service technology in smart close range that facilitates functions such as message transmission and mobile payment by identifying the locations of a user within the close range of 50 to $100 \mathrm{~m}$. Beacon application technology can be used to provide various application service technologies such as context awareness related to objects, content push, indoor location technology, auto check in, and GeoFence.

\subsection{Beacon}

\subsubsection{Definition of Beacon}

The term "beacon" indicates a transmission method accompanied by location and information, such as a signal fire and bonfire. The word has the dictionary meaning of lighthouse, light bar, and radio station and has mainly indicated a wireless signal since the $21^{\text {st }}$ century.

\subsubsection{Characteristics of Beacon}

Beacon service is a smart short-range communication service technology based on the Bluetooth Low Energy (BLE) 4.0 protocol, which facilitates functions such as message transmission and mobile payment by identifying the locations of users within the short range of 50 to $100 \mathrm{~m}$. A beacon has a recognition range of 50 to $100 \mathrm{~m}$, shows higher accuracy than existing Near Field Communication (NFC) and Bluetooth 3.0, and uses the Bluetooth Low Energy (BLE) technology. As it can be used as with a small battery for several years, it has been widely applied to NFC technology. Moreover, it is appropriate for implementation of the Internet of Things (IoT) because of its high accuracy, low battery consumption, and capacity of transferring data signals by identifying the locations of tablet personal computers and wearable devices [3-4].

\subsubsection{Beacon Technology}

Beacon technology can be used to provide various application service technologies such as context awareness related to objects, content push, indoor location technology, 
auto check in, and GeoFence. In particular, beacons serve as reference points that provide location-related information. When a target reaches a location that is within several meters of where a beacon device is attached, a specific signal is received, and the location of the device can be identified on the basis of this signal. To transfer such information, communication technologies including Dedicated Short Range Communications (DSRC), ultrasonography, infrared ray, Bluetooth, Code Division Multiple Access (CDMA), Long Term Evolution (LTE), Wireless Fidelity (WiFi), and Light Fidelity (LiFi) are used. Recent beacon technologies apply various technologies such as beacons using BLE technology, as represented by iBeacon, those using ultrasonography or visible light, and radio frequency $(\mathrm{RF})$ beacons based on a different frequency [5].

\subsubsection{Application of Beacon Technology}

Beacons are utilized for indoor location technology very effectively. For example, when a smart app receives a beacon signal and demands a response with detailed information received at a dedicated server, this server obtains the information and displays the details by transferring them to the user's app. This technology can be applied in various information services for sending product information and event coupons and managing transfer history. Thus, if beacons contain information on latitude and hardness and are equipped with short-distance location technology and object recognition sensors, they will be spotlighted as an effective core technology for online and off-line information services in the future. Table 1 gives examples of beacon applications provided by the NOMURA Research Institute in Japan.

Table 1. Evolution of Service Based on Next-Generation Retail IT

\begin{tabular}{|l|l|l|}
\hline Use Case & \multicolumn{2}{|c|}{ Contents } \\
\hline $\begin{array}{l}\text { Advertising } \\
\text { Provide Content }\end{array}$ & Welcome & Welcome greetings and store hours \\
\cline { 2 - 3 } & Boring\&Soothe & $\begin{array}{l}\text { Smartphone app to attract customers and waiting } \\
\text { time soothe }\end{array}$ \\
\cline { 2 - 3 } $\begin{array}{l}\text { Customer } \\
\text { Induction, } \\
\text { Decentralization }\end{array}$ & $\begin{array}{l}\text { Induce } \\
\text { customers }\end{array}$ & $\begin{array}{l}\text { Alarm display to guide the advertisement product } \\
\text { location, attract customers to less crowed and } \\
\text { slovenly places }\end{array}$ \\
\cline { 2 - 3 } $\begin{array}{l}\text { Sounted on } \\
\text { Service } \\
\text { (One2One) }\end{array}$ & $\begin{array}{l}\text { Send coupon to customer } \\
\text { identification }\end{array}$ & $\begin{array}{l}\text { Alarm notification to employees when visiting } \\
\text { customers, Communicate customer history to } \\
\text { employees }\end{array}$ \\
\cline { 2 - 3 } & $\begin{array}{l}\text { Individual } \\
\text { service } \\
\text { provision }\end{array}$ & $\begin{array}{l}\text { Provide services corresponding to past history and } \\
\text { credit score }\end{array}$ \\
\hline $\begin{array}{l}\text { Satisfaction } \\
\text { Survey }\end{array}$ & $\begin{array}{l}\text { Customer } \\
\text { Survey }\end{array}$ & $\begin{array}{l}\text { Customer satisfaction survey letter sent when } \\
\text { visiting or leaving }\end{array}$ \\
\cline { 2 - 3 } & Store analysis & $\begin{array}{l}\text { Time zones, and customers' visit to each store, etc., } \\
\text { to improve customer satisfaction or utilize them as } \\
\text { basic data for resource allocation }\end{array}$ \\
\cline { 2 - 3 } & $\begin{array}{l}\text { Use } \\
\text { information }\end{array}$ & $\begin{array}{l}\text { Use time spent by customer in store or history of } \\
\text { use as basic information of mobile, web, and } \\
\text { telephone customer }\end{array}$ \\
\hline
\end{tabular}




\subsection{Internet of Thing}

\subsubsection{Definition of Internet of Thing (IoT)}

Internet of Things (IoT) is based on the concept of ubiquitous computing, in which all the objects around us are connected to each other through a network and combined with computer technology, which was proposed by Mark Weiser in 1991. This concept was enhanced to become the Internet of Things (IoT) by Kevin Ashton at the Auto-ID, lab that assigns IDs to objects and has been used so far [7-8]. Internet of Things (IoT) enables many sensors, objects, and devices to form a network with adjacent devices and to interact with their surroundings. We call it IoT or Internet of Thing. In other words, this technology enables the relationships between objects as well as between objects and human beings to exchange various types of information through the Internet and sensors. Figure 1 shows how the Internet of Things (IoT) is used to connect different industries with consumer goods.

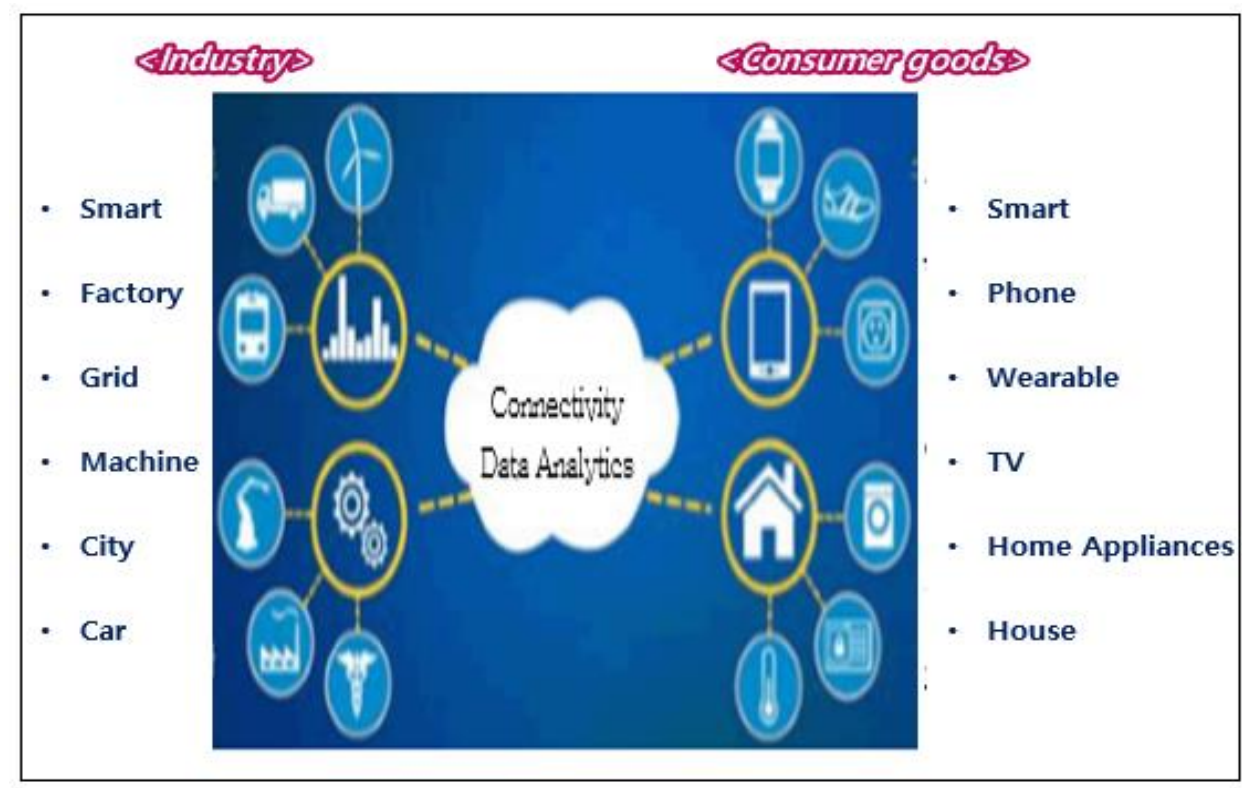

Figure 1. Concept of Things Internet

\subsubsection{Characteristics of Internet of Thing(IoT)}

Internet of Things (IoT) technology re-emerged as the extended concept of Machine to Machine (M2M) and Ubiquitous Sensor Network (USN) led to an increase in the speed of wired and wireless networks and the supply of smart devices. Many applications are being developed in the environments established to support services whenever, wherever, and whatever they are demanded, and these technologies have been enhanced to expand the range of Internet of Things (IoT) [10]. Therefore, we should pay attention to IoT's potential market.

\subsubsection{Structure of Internet of Thing(IoT) Plarform}

The structure of an Internet of Things (IoT) platform can be described as a process whereby data measured by a sensor are transferred to a complete service. In terms of functions, this process is classified into data creation, data connection, data collection, data storage, data manufacturing, and data processing [11]. Internet of Things (IoT) platform technologies are classified into object recognition technology, object data 
abstraction technology, object management and security technology, and service supply technology [12].

\subsection{Status of Beacons and Internet of Thing (IoT) in South Korea}

Internet of Things (IoT) technology is gaining popularity in Korea in the industries of Internet, home care, and farming. Internet Smart Palm is a system developed by SK Telecom (SKT), which enables users to remotely control a vinyl greenhouse by using their smartphones. Health-On, developed by the Seoul National University Hospital, is a health care system that analyzes individuals' health by using measuring instruments that users wear on their wrists or waists. Other examples include the Food Management System and Vehicle Control System, which use a mobile radio communication network developed by LG Uplus, and the NFC-based Home Sync Service by Samsung Electronics CO., Ltd. Furthermore, KT and Hyundai Motor Company have introduced Blue Link, a system that manages vehicle parking position and vehicle anti-theft systems based on smartphones or personal computers. It is planned that the amount of investment will steadily increase from 2.3 trillion KRW in 2013 to 30 trillion KRW by 2020 to support the Korean Internet of Things (IoT) market [13-15].

\section{Design and Implementation of a User-Specific Information Service Using Beacon and Internet of Thing (IoT) Technologies}

\subsection{Overview Proposed System}

The information system proposed in this study provides users with desired information by using 4.0 BLE location-based technology to automatically recognize the locations of users moving around a university. A university campus was used to apply this system. Universities are willing to provide various types of information to university members, students, processors, and staffs. For example, they provide students with information on classrooms, class automatic attendance, library use, and various convenience facilities operated in the universities as well as notices according to the academic calendar in order to boost learning efficiency. Professors are provided with information on students for student management, classes, and grades as well as tools for learning assistance. Universities also attempt to provide various services enabling professors to share lecture details with students by saving class information in the university's cloud system before starting their lectures and to set counseling appointments with students by sharing their schedule with students through smart devices. Furthermore, the professors are willing to identify the tracks of university members so that student can provide convenient information based on the tracks and achieve efficient educational management. The customized information service system designed and implemented in this study automatically provides university members with desired information in the right place at the right time by using Internet of Things-based beacons.

\subsection{Overview Proposed System}

The education information system proposed in this study combines beacons and Internet of Things (IoT) technology. Figure 2 shows the entire configuration of this system including the user, smart device, beacon, main operating system, user app, and SMS push system (Short message service system). The entire flow of services can be described as follows.

(1) A user registers information via his/her smart device in the main operating system to use the system. At this time, an information service app should be set up in the user's smart device. 
(2) The main operating system stores information on the user's smart device if the user confirms the information and is authorized by the university. This process is called user registration.

(3) When a user arrives in the area of a beacon installed at the university, the beacon transfers information about its location to the user's smart device. At this time, Bluetooth should be turned on in the user's smart device.

(4) The app in the user's smart device transfers the user's identification information to the main operating system.

(5) The main operating system authorizes the user identification transferred and requests information about the beacon location from the user when the authentication process is confirmed.

(6) The user transfers information about the beacon's location to the main operating system.

(7) The main operating system searches for information related to the user's location using the information about the beacon's location and transfers information required by the user to the user's smart device.

\subsection{Overview Proposed System}

The education information system proposed in this study combines beacons and Internet of Things (IoT) technology. Figure 2 shows the entire configuration of this system including the user, smart device, beacon, main operating system, user app, and SMS push system (Short message service system). The entire flow of services can be described as follows.

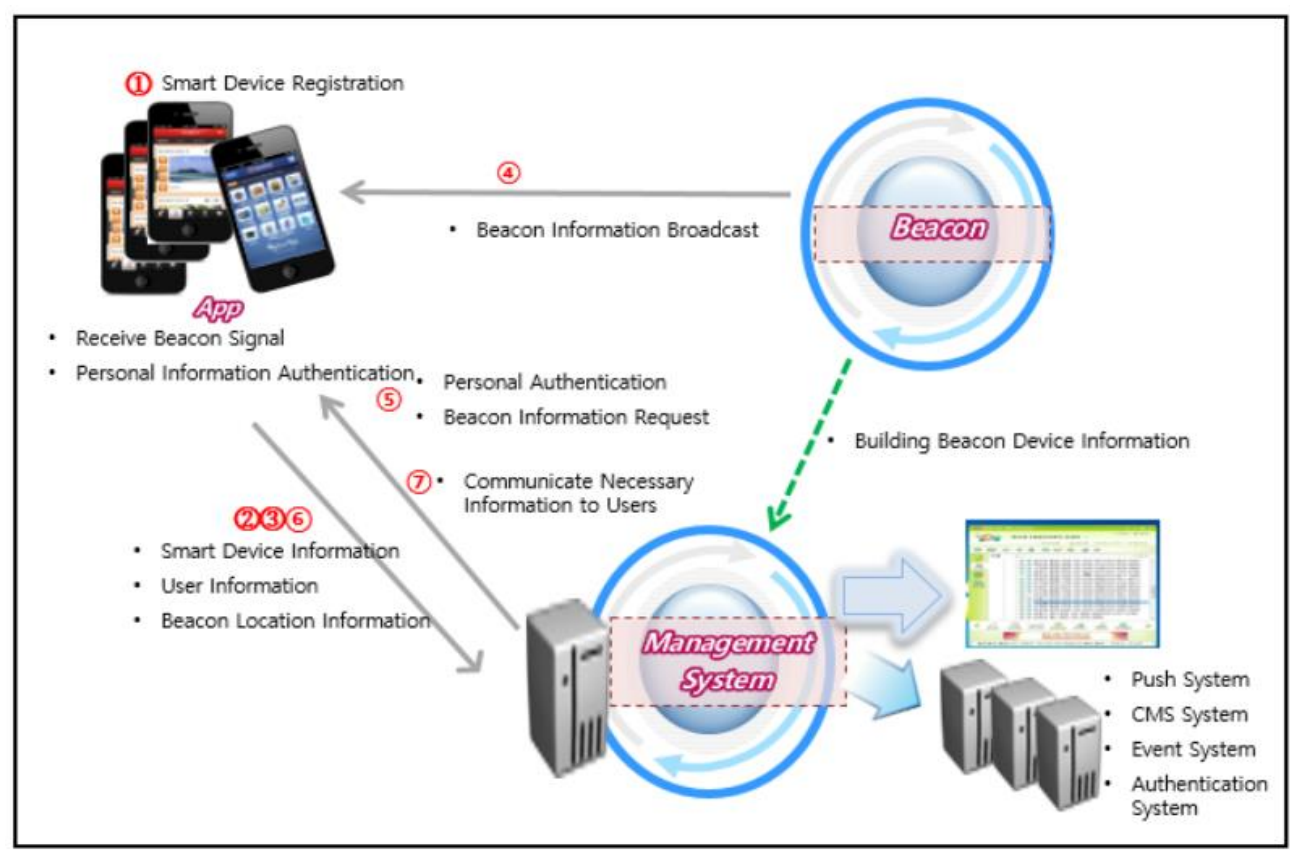

Figure 2. Suggestion System Technical Diagram 
Table 2. Proposal System Development Environment

\begin{tabular}{|l|c|}
\hline \multicolumn{2}{|c|}{ Proposal System Development Environment } \\
\hline Development Language & AVA, JDK 1.7 \\
\hline Database and Web Server & Oracle 10g / WebSphere 6.1 \\
\hline HardWare & IBM P-570 AIX 5.6 \\
& CPU : 4.2GHz PowerPC_POWER6 * 2cpu \\
& MEM : 8960 Mbytes \\
& HDD : 146.8GB SAS Disk Drive * 2EA \\
& Operating System : AIX 5300-08-08-0943 \\
& Kernel : 64bit \\
\hline Etc & Beacon 4.0, Android 4.3, ios 7.0 \\
\hline
\end{tabular}

Table 3. Flow of Service Proposal System

Flow of Service Proposal System

- Information on the user's smart device is registered in the main operating system.

- The main operating system stores information on the user's smart device, and the user confirms the information

- The beacon broadcasts its location to the user's smart device within a radius of 50-70m and transfers it to the user.

- The user service app transfers information about the beacon broadcast at close range to the operating system.

- The operating system confirms the user information and transfers it to the content management system (CMS) on the basis of the beacon information received.

- The operating system searches for data according to the user's location by using the push system and transfers the information required by the user to the smart device.

\subsection{Implementation of Proposed System}

The education information system proposed in this study has a configuration that combines beacons with Internet of Thing (IoT) technology. This study implemented the user-specific information service system that transfers information about the university that is desired by the user, such as classroom information, classroom location automatic attendance, notices, scholarship guidance, library information, academic calendar, building information, and mobile payment, to the user's smart device.

In the implementation of this system, its configuration had five stages: smart device registration, user service app, user location checking, user authentication, and transfer of information required by the user. In addition, the proposed system focuses only on services related to notices, guidance, and library information from among the entire range of services. 
signal is received, the app installed in the user's smart device sends a signal to the operating system. The operating system recognizes the user information received, searches for appropriate service information, and transfers the result to the app installed in the user's smart device to provide him or her with the information.

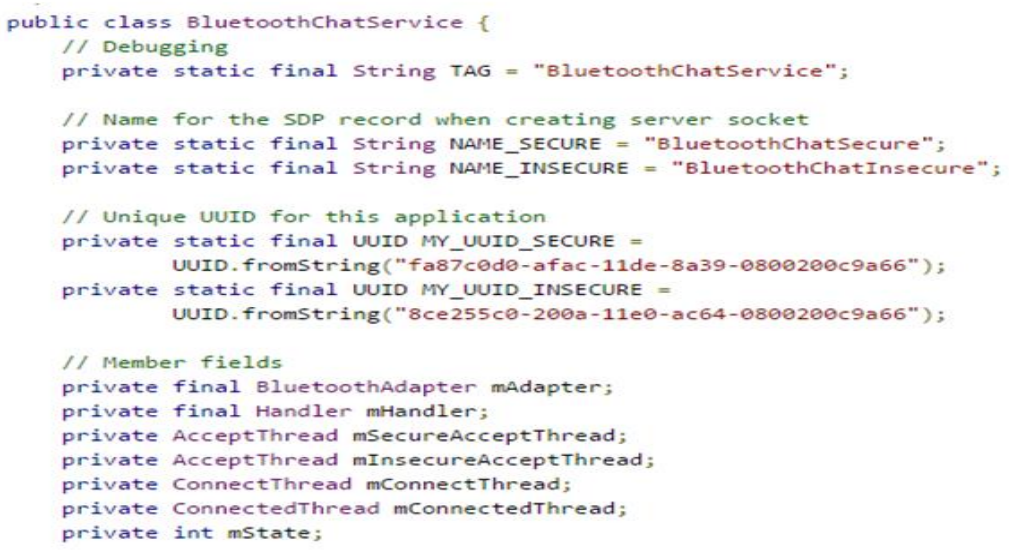

Figure 3. Information of User UUID Function Program

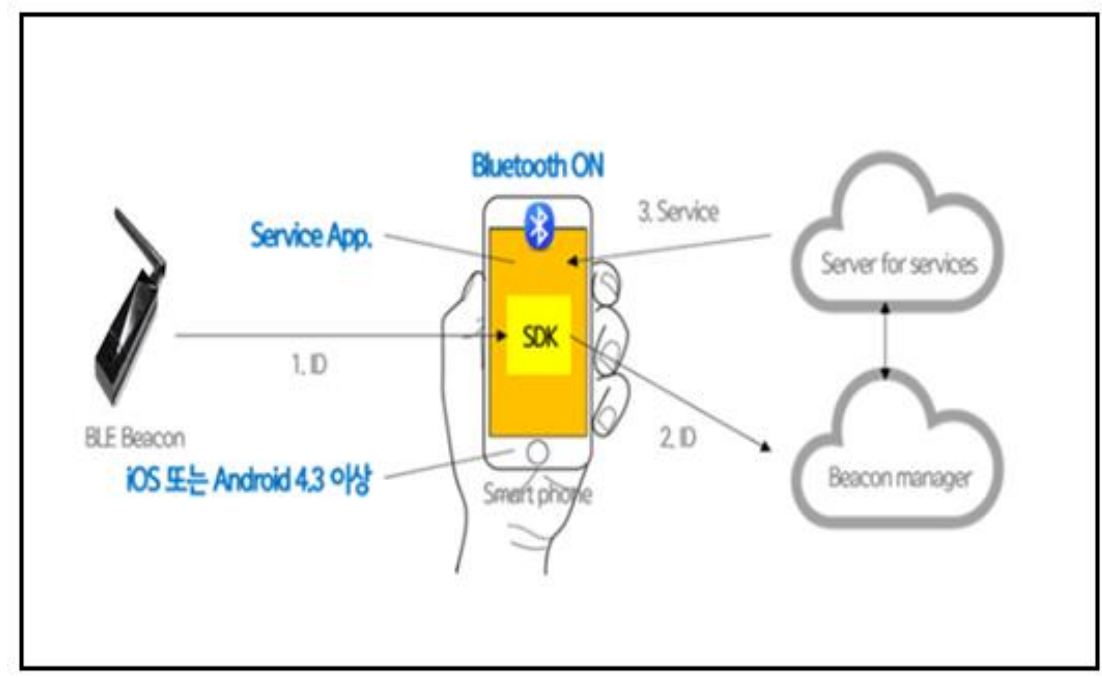

Figure 4. Shows the Principle of Beacon Operation

\subsubsection{User-Specific Information Service}

The education information system proposed in this study combines beacons with Internet of Thing (IoT) technology. This study implemented this system, which transfers information about the university that is required by the user, such as classroom information, classroom location, class time, automatic attendance, notices, scholarship guidance, library information, academic calendar, and building information, mobile payment, to the smart device of the individual user. The beacon regularly transfers its own information. When the user is recognized in the area of a beacon and information is completely transferred, the main operating system recognizes the user information received and sends appropriate service information to the user's smart device to provide him or her with desired information. This proposed system provides such information as part of a user-specific information service. This study implemented the proposed system 
by applying it to the university guide service and library information service from among the entire range of services related to the education information system provided in universities. Conditions (1)-(3) indicate the environmental configuration of the smart device that the user should establish to use this proposed system:

(1) The OS of the smart device used iOS 7.0 or Android 4.3 higher.

(2) The Bluetooth feature of the smart device used should be turned on.

(3) The service app should be set up in the smart device used.

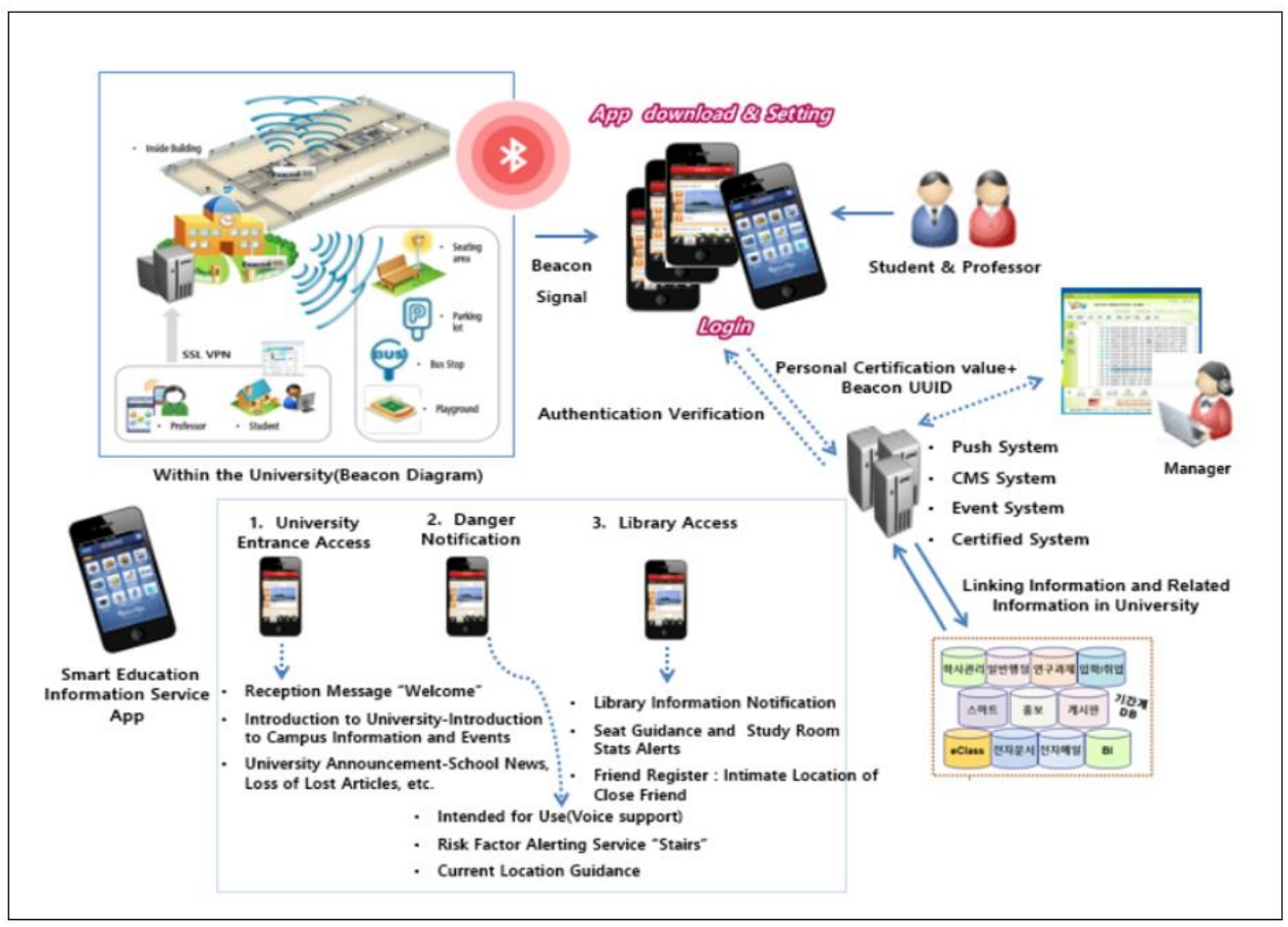

Figure 5. Shows the Principle of Beacon Operation

\subsection{Result of Implementation of Proposed System}

The result of implementing the user-specific information service provided through this proposed system or applying this system to the university guide service and library information service from among the entire range of services related to the education information system is as follows. Figure 5 shows the result of implementing the beacon service at the university. When a user accesses the university gateway, a welcome greeting notice service, which displays "Welcome. This is ABC University." on the user's smart device, is performed. Moreover, the user is provided with services that indicate information on the campus guide, events, campus location guide, university-related news, and lost property. This system informs physically challenged people about risk factors and blind people about the current location through the voice function. In addition, when a user reaches the library, this system provides a service that shows information on the list of accessions, seat allocations in the library, and the status of study room reservations. If the function for close friend registration is enabled, information on the location of friends in the library is provided. Furthermore, this proposed system provides services that indicate information about the buildings, classrooms in the buildings, automatic attendance, lectures, and campus location. 


\section{Conclusions}

The proposed system provides desired information to users by detecting the location of moving users via Bluetooth 4.0 technology. In the past, information communication was a one-sided delivery service regardless of users' intentions, but the proposed system can provide customized information services to users by quickly delivering the desired information at the desired time.

This study implemented the education information system provided for university members, students, and professors at university by using location technology, which is applied most effectively by using beacon technologies. Universities are willing to help university members easily use various information services for academic calendars, class information, library information, university events, building information, and location guidance, which are provided at universities, using the members' smart devices. It is anticipated that this proposed system could be applied throughout the entire range of education sites, including universities. In particular, the indoor location guide service can be effectively used by young students who first enter an elementary school. The wider utilization of this system will be regarded as a primary, practical case for applying Internet of Thing (IoT) at education sites. However, attention should be paid to network security when this system is used at a university. It appears that the level of network security in Korean universities is not very high. Moreover, as hackers are familiar with the Internet structure at a university, the risk of information leakage could increase. It should also be noted that critical information leakage on the user can occur because the replication and analysis of primitive code can be easily carried out under the presumption that the app installed in the smart device provides a route to the user. Therefore, as smart devices are increasingly used, the importance of security and management needs to be deeply recognized.

\section{References}

[1] D. Ryu, "Development of BLE Sensor Module based on Open Source for IoT Applications," J. of the Korea Institute of Electronic Communication Sciences, vol. 10, no. 3, (2015), pp. 419-424.

[2] J. Kim, "A Smart Home Prototype Implementation Using Raspberry Pi," J. of The Korea Institute of Electronic Communication Sciences, vol. 10, no. 10, (2015), pp. 1139-1144.

[3] Eun-Seok Kim, Seok-Cheon Park, Sung-Chul Kim, "Trends of Application Technology and Service Based on Beacon”, Korea Society for Internet Information, vol. 17, no. 1, (2016), April, pp. 335-346.

[4] Soo-A, Seok-Cheon Park, Jong-Hyun Kim, "Design and Implementation of Smart Access System Using Bluetooth Beacon in IoT Environment", Korea Society for Internet Information, (2015), May, pp. 3265266.

[5] J. A. Lee, "Injury of the Beacon Service and New Business Spread", National Information Society Agency, Vol. 8, (2014), October.

[6] Nomura Research Institute Tech Report, "Evolution of Customer Services based on Next Generation Retail IT", Nomura Research Institute, (2014), May.

[7] Weiser, M., "The computer for the 21st century", Scientific American, (1999), 265(3), pp. 94-104.

[8] A Shton, Kevin. That internet of things, RFID Journal, (2009), 22: pp. 97-114.

[9] "NIDays2014 for Engineers in the Industrial IoT era", NIDays.

[10] S. H. Bae, "Core Object of the Smart-Age Expansion of Internet Market Expansion through Convergence with the Busan Main Industry", BUSAN DEVELOPMENT FORUM, vol. 153, (2015) May, pp. 16.

[11] H. Y. Kim, "Internet of Things Concept, Implementation and Business", Hongrung Publishing Company, (2003), pp73.

[12] S, C, Choi, "Internet Platform and Service Trends", Korea Electronics Technology Institute, vol. 31, no. 4, (2014), April, pp. 20-27.

[13] W, G, Jang, S. H, Lee, "Internet Policy and Market Trends and Key Service Cases in Domestic and Foreign Countries", Korea Communications Agency, vol. 64, (2013), July, pp. 30.

[14] D, Y, Joo, J, G, Kim, "Creative Fusion of the Internet of the Time of the Second Connection Activation Plan”, Issue Paper 2014-342, Korea Institute for Industrial Economics \& Trade, (2014), vol. 1, pp. 89-93.

[15] "The Internet Basic Plan for Realizing the Leading State of the Digital Revolution", Ministry of Science, ICT and Future Planning, (2014), May, pp. 4-6. 


\section{Authors}

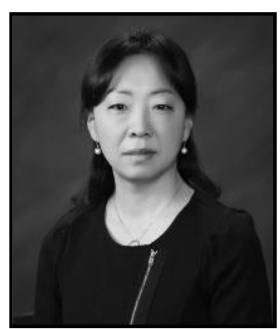

Hyun Joo Kim, she is a Team Leader of the Computerized Information Office, Hyupsung University, Hwaseong-Si KyeonggiDo, Korea. Her received his Ph.D. degree in Electronic \& Computer Engineering at Dankook University, Her recent interests are in big data, mobile payment, java card, ubiquitous, smart information system, internet of thing, security in general and cloud computing. She can be reached chopinkhj@ gmail.com. **first author

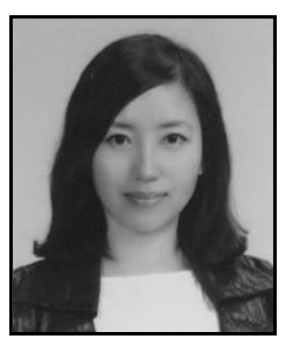

Min Sun Kim, She got her Ph.D. in Management Information System from Ewha Womens University, Korea. She is currently is a faculty member in School of Tourism and Distribution Management, College of Business Administration, Hyupsung University, Korea. Her current research interests include Smart work, ubiquitous, e-business, distribution management including CRM, and Hotel and Tourism management. She can be reached at sunnyminkim@ hanmail.net. *corresponding author 